\title{
NOTE \\ Risk factors associated with reproductive performance in Japanese dairy cows: Vaginal discharge with flecks of pus or calving abnormality extend time to pregnancy
}

\author{
Hiroaki OKAWA ${ }^{1,2)}$, Akira GOTO ${ }^{3)}$, Missaka M.P. WIJAYAGUNAWARDANE4), \\ Peter L.A.M. VOS ${ }^{5)}$, Osamu YAMATO ${ }^{1,6)}$, Masayasu TANIGUCHI ${ }^{1,7)}$ and \\ Mitsuhiro TAKAGI ${ }^{1,7) *}$
1)United Graduate School of Veterinary Science, Yamaguchi University, Yamaguchi 753-8515, Japan ${ }^{2)}$ Fukuoka Prefecture Dairy Cooperative Association, Fukuoka 839-0832, Japan
${ }^{3)}$ Veterinary Medical Center, Obihiro University of Agriculture and Veterinary Medicine, Obihiro, Hokkaido 080-8555, Japan
4)Department of Animal Science, University of Peradeniya, Peradeniya, 20400, Sri Lanka
6) Joint Faculty of Veterinary Medicine, Kagoshima University, Kagoshima 890-0062, Japan
7) Joint Faculty of Veterinary Medicine, Yamaguchi University, Yamaguchi 753-8515, Japan \\ ${ }^{5)}$ Department of Farm Animal Health, Utrecht University, Yalelaan 7, 3584 CL Utrecht, the Netherlands
}

\section{J. Vet. Med. Sci.}

81(1): 95-99, 2019

doi: 10.1292/jvms.18-0259

Received: 8 May 2018

Accepted: 15 November 2018 Published online in J-STAGE: 26 November 2018
ABSTRACT. The present study aimed to determine possible risk factors affecting reproductive performance, especially time taken to establish pregnancy in dairy cows, using Cox's proportional hazard model. The data were collected from 154 Holstein Friesian cows (199 lactations). Cows diagnosed with a vaginal discharge score (VDS) of one or calving abnormality showed significantly delayed pregnancy: hazard ratio $(\mathrm{HR})=0.654$ (95\% confidence interval $[\mathrm{Cl}]: 0.436-0.983 ; P=0.041$ ) and $\mathrm{HR}=0.457(95 \% \mathrm{Cl}: 0.270-0.774 ; P=0.004)$, respectively. Our study suggested that the occurrence of VDS of one or calving abnormality might be possible risk factors increasing the number of days open and affecting reproductive performance in dairy cows.

KEY WORDS: calving abnormality, days open, fertility, risk factor, vaginal discharge score

Optimal reproductive efficiency is a prerequisite for guaranteeing the profitability of the dairy industry. Multiple farm management-related and environmental factors, including perinatal management, affect reproductive performance [8]. Previously, we focused on diagnostic methods for clinical postpartum endometritis using a grading system based on vaginal discharge score (VDS), and found that untreated cows having a VDS of one showed a negative reproductive progression [18]. In addition, we reported that the retention of fetal membranes, as well as other early postpartum conditions within 30 days of parturition, was related to the occurrence of clinical endometritis [17]. However, poor reproductive performance can be caused by conditions other than clinical endometritis, and many other related factors can contribute to postpartum diseases and conditions [10, 11, 22]. Although many studies were conducted on the relationship of clinical endometritis with reproductive performance, whether having a VDS of one is related to negative reproductive prognosis, and whether should be treated or not, have remained controversial until date $[5,13,16]$. Few studies have focused on the effects of the cows having VDS of one during the early postpartum period, and therefore, the other factors affecting reproductive performance, especially the length of the postpartum interval to established pregnancy need to be investigated [5-7, 19, 20]. Among many related factors, including the detection of a VDS of one, which affect reproductive performance, it is necessary to identify the factors that have a greater effect. Therefore, the objective of this study was to determine the possible risk factors affecting reproductive performance, with a focus on the effect of the time needed to establish a successful pregnancy (number of days open) using Cox's proportional hazard model.

In the present study, the data used were extracted from a data set obtained in our previous study [18]. Records for 154 Holstein Friesian cows (total 199 lactations) that calved during a 26-month-period from September 2013 to November 2015, were used for analysis. The cows (parity, 1-6) were reared in four commercial dairy herds in Fukuoka Prefecture, Kyushu, which is the largest island in southern Japan. The size of the lactating herd varied from 20-50 cows. The herds used was non-seasonal, milked twice a day, and the average annual milk production varied between $8,100-10,900 \mathrm{~kg}$ per cow. The voluntary waiting period for each herd

*Correspondence to: Takagi, M.: mtakagi@yamaguchi-u.ac.jp

(c2019 The Japanese Society of Veterinary Science

This is an open-access article distributed under the terms of the Creative Commons Attribution Non-Commercial No Derivatives (by-nc-nd) License. (CC-BY-NC-ND 4.0: https://creativecommons.org/licenses/by-nc-nd/4.0/) 
was set at 40 days postpartum. The cows were bred by artificial insemination (AI), which was performed by local technicians. Each herd was visited on a monthly basis for a clinical reproductive survey, including treatment of reproductive disorders and pregnancy diagnosis. Pregnancy was diagnosed by transrectal palpation or ultrasonography, 40 days after insemination. For cows that were not inseminated within 90 days postpartum, or cows not pregnant at the time of pregnancy diagnosis, an additional clinical investigation and treatment was performed. In brief, the cows in which estrus was hard to detect (anestrus) were treated by a timed AI program using combined injections of PGF2 $\alpha$ and estradiol.

Information for each individual, including the parity number, calving season, status of vaginal discharge based on VDS test, medical records for retained placenta and early postpartum diseases within 30 days of parturition, calving abnormalities including dystocia, stillbirth, and twinning, and the use/absence of a timed AI program within 150 days of parturition, were included in the data used in the present analysis. Parity numbers were classified into four different categories (1, 2, 3, and $>4)$. Calving seasons were classified into four categories (Spring, March-May; Summer, June-August; Autumn, September-November; Winter, December-February). The VDS test was conducted in all the cows 21-60 days (mean 39.3 \pm 9.2 ) after parturition by using the method for examination described in our previous study [18]. The VDS was used to classify the status of vaginal discharge: $0=$ no or clear mucus; 1 =mucus containing flecks of white or off-white purulent material; 2 =discharge containing less than $50 \%$ purulent material; and $3=$ discharge containing more than $50 \%$ purulent material $[13,24]$. In the present study, we focused specifically on the effect of VDS of one. Cows with a VDS of two or above were excluded from the analysis. The mean postpartum days of cows with $\operatorname{VDS}=1(n=169)$ and $\operatorname{VDS}=0(n=30)$ at the time of VDS test were $37.2 \pm 9.4$ and $39.7 \pm 9.2$ respectively, and the difference was not significant. Medical records on retained placenta and other early postpartum diseases observed in each individual cow within 30 days of the parturition period were obtained from the records of the Federation of Agricultural Mutual Relief Association. Individuals that retained placenta, defined as the retention of fetal membranes $>24 \mathrm{hr}$ after parturition, were administrated an intramuscular PGF2 $\alpha$ injection within a period of seven days after parturition. Early postpartum diseases observed within 30 days parturition included milk fever, puerperal fever (metritis), hyperketonemia (ketosis), and acute mastitis. Dystocia was defined as a calving that required veterinary assistance. Stillbirth was defined as a dead fetus found at calving or immediately after calving. Information on the calving conditions and hence information on productivity was obtained from the Livestock Improvement Association of Japan (LIAJ). A limited number of cows $(n=54)$ used in this study underwent a timed AI program within 150 days of parturition because of anestrus. The intramuscular administration of $2 \mathrm{mg}$ of estradiol benzoate (Ovahormon ${ }^{\circledR}$; ASUKA Animal Health Co., Ltd., Tokyo, Japan) and insertion of a controlled internal drug-releasing device (CIDR; CIDR ${ }^{\circledR}$ 1900; Zoetis Japan Co., Ltd., Tokyo, Japan), were conducted on day 0; the intramuscular administration of $500 \mu \mathrm{g}$ of cloprostenol (Estrumate ${ }^{\circledR}$; Intervet K.K, Tokyo, Japan) was performed on day 9, along with CIDR removal; $1 \mathrm{mg}$ of estradiol benzoate was administered on day 10 and was followed by AI on day 11.

All statistical analyses were performed using the Bell Curve for Excel software program (Social Survey Research Information Co., Ltd., Tokyo, Japan). The dates regarding the time to establish the pregnancy were analyzed using Cox's proportional hazards regression model. Pregnancy was set as an endpoint, and the culling rate owing to infertility or post-partum diseases was set as censoring. The explanatory variables used were parity number, calving season, VDS of one, retained placenta and early postpartum diseases, calving abnormality, and occurrence of a timed AI program within 150 days of parturition. Each explanatory variable was initially examined using univariate analysis. The associated variables $(P<0.1)$ were used for multivariable analysis based on the Cox's proportional hazards regression model of time to pregnancy. In addition, significant variables of multivariable analysis were visualized using Kaplan-Meier survival curves, and the differences were analyzed using a generalized Wilcoxon test. $P<0.05$ was considered statistically significant.

Univariate analysis selected parity, season of calving, VDS of one, retained placenta, and calving abnormality for multivariable analysis (Table 1 ). The multivariable analysis showed that VDS of one (hazard ratio $=0.654 ; P=0.041$ ) and calving abnormality (hazard ratio $=0.457 ; P=0.004$ ) were significantly associated with the number of days open postpartum to establish the pregnancy (Table 2). Moreover, in the survival analysis (Fig. 1), both VDS of one and calving abnormality increased the time to pregnancy significantly ( $P=0.018$ and 0.0096 , respectively) as compared with that of the control group.

Consistent with the findings of our previous study [18], the cows with a VDS of one included in the present study showed a reduced reproductive performance. Although the occurrence of clinical endometritis was shown to be associated positively with the retention of fetal membranes and early postpartum diseases within 30 days of parturition in our previous study [17], the findings of this study indicate that calving abnormality and VDS of one were associated with extending the number of days open postpartum to establish a pregnancy. In Japan, especially in the experimental area, the average calving to conception interval in dairy cows is approximately 160 days [14] and the median calving to conception interval in dairy cows is approximately 177 days [8]. Although the use of a timed AI program within 150 days after parturition was generally considered an economically important factor that could improve reproductive performance, no association of the timed AI program with the number of days open was observed in the present study. Conditions such as stillbirth and dystocia have negative effects on reproductive performance [4, 22], and therefore, milk production [4]. In addition, Hossein-Zadeh et al. [11] reported that dairy cows that gave birth to twins had an increased number of days open as compared with those that gave birth to a single calf (129.28 days vs. 144.88 days). In dairy management, the effective prevention of twinning might be difficult, because parity number and level of milk production appear to be positively associated with increased ovulation rate, and therefore, twinning rate $[2,12,26]$. In addition, twinning is positively associated with a higher risk of dystocia and increased neonatal mortality [4,23]. In the present study, we have shown the negative effect of calving abnormality and VDS of one on the postpartum time to establish a pregnancy. Although calving abnormality had no significant association with the risk of clinical endometritis, as shown in one of our previous studies [17], the present study 
Table 1. Result of univariate analysis with Cox's proprortional hazards model of time to pregnancy

\begin{tabular}{lccccc}
\hline \multicolumn{1}{c}{ Variable } & Category & $\mathrm{n}$ & HR time to pregnancy $^{\mathrm{a})}$ & $95 \%$ CI & $P$-value \\
\hline Parity & 1 & 60 & Reference & - & - \\
& 2 & 56 & 0.682 & $0.467-0.995$ & 0.047 \\
& 3 & 41 & 0.984 & $0.648-1.494$ & 0.940 \\
\multirow{5}{*}{ Season } & $>4$ & 42 & 0.738 & $0.490-1.110$ & 0.144 \\
& Spring & 30 & Reference & - & - \\
& Summer & 50 & 1.104 & $0.681-1.790$ & 0.690 \\
& Autum & 76 & 1.248 & $0.805-1.935$ & 0.322 \\
Mild vaginal discharge & Winter & 43 & 0.593 & $0.357-0.987$ & 0.044 \\
\multirow{4}{*}{ Retention of fetal membranes } & No (VDS=0) & 169 & Reference & - & - \\
\multirow{4}{*}{ Postpartum disease within 30 DIM } & Yes (VDS=1) & 30 & 0.68 & $0.454-1.017$ & 0.06 \\
& No & 191 & Reference & - & - \\
Calving abnormality & Yes & 8 & 0.497 & $0.220-1.125$ & 0.093 \\
& No & 161 & Reference & - & - \\
Timed AI program within 150 DIM & Yes & 38 & 1.315 & $0.906-1.908$ & 0.15 \\
& No & 181 & Reference & - & - \\
& Yes & 18 & 0.498 & $0.296-0.836$ & 0.008 \\
& No & 145 & Reference & - & - \\
& Yes & 54 & 1.256 & $0.911-1.732$ & 0.164 \\
\hline
\end{tabular}

a) HR time to pregnancy: Hazard ratio time to pregnancy.

Table 2. Result of multivariate analysis with Cox's proportional hazards model of time to pregnancy and median survival times

\begin{tabular}{lcccc}
\hline \multirow{2}{*}{ Variable } & \multirow{2}{*}{ Category } & \multicolumn{2}{c}{ Cox's proportional hazards model } \\
\cline { 3 - 5 } & & Ho time to pregnancy & $95 \%$ CI & $P$-value \\
\hline Calving abnormality & Yes & reference & 0.004 \\
\multirow{2}{*}{ Retention of fetal membranes } & No & 0.457 & $0.270-0.774$ & \\
& Yes & reference & 0.059 \\
Mild vaginal discharge & No (VDS=0) & 0.452 & $0.199-1.029$ & \\
& Yes (VDS=1) & reference & & 0.041 \\
& & & $0.436-0.983$ & \\
\hline
\end{tabular}

a) HR time to pregnancy: Hazard ratio time to pregnancy.

(A)

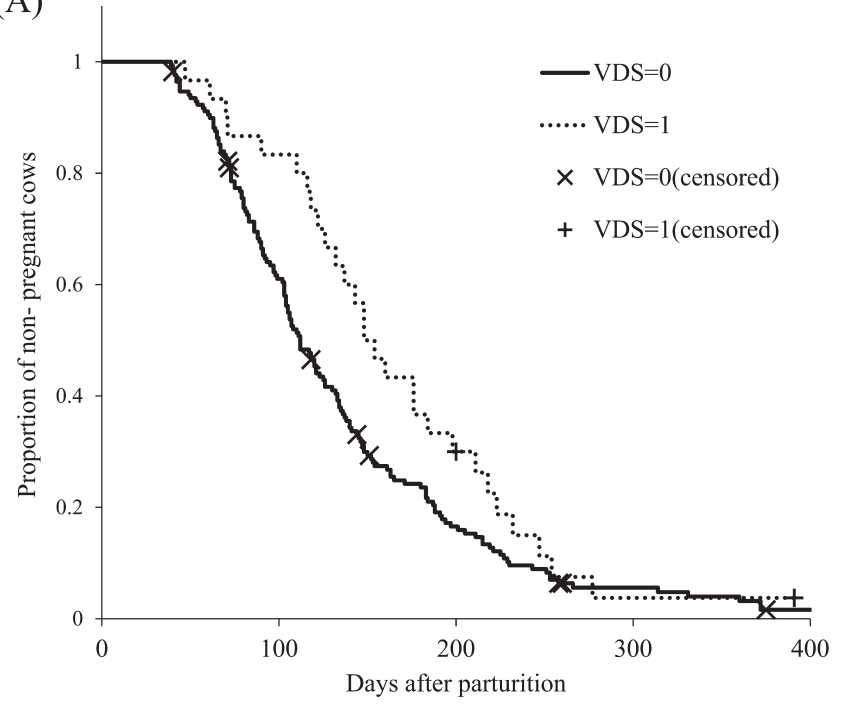

(B)

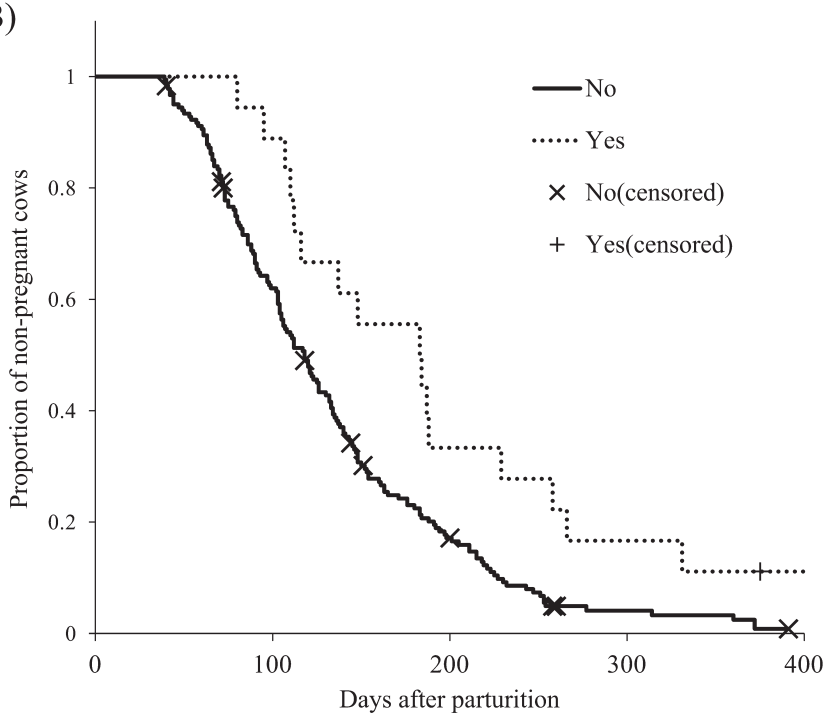

Fig. 1. (A) Kaplan-Meier survival curves for the population of open cows with no vaginal discharge (vaginal discharge score [VDS]=0) or VDS $=1$. Cows with no vaginal discharge: solid line, $n=169$; median open days $=112 ; 5.3 \%(n=9)$ of the cows studied were censored. Cows with VDS of 1: broken line, $n=30$; median open days $=148 ; 6.7 \%(n=2)$ of the cows studied were censored. (B) Kaplan-Meier survival curves for the population of open cows with normal calving and calving abnormality. Cows with normal calving: solid line, $\mathrm{n}=181$; median open days $=118 ; 5.5 \%(n=10)$ of the cows studied were censored. Cows with calving abnormality: broken line, $\mathrm{n}=18 ;$ median open days $=183 ; 5.6 \%$ $(\mathrm{n}=1)$ of the cows studied were censored. 
indicated that calving abnormality negatively affected reproductive performance. These findings suggest that cows that experienced calving abnormality have potential risk factors, such as subclinical endometritis, due to the abnormal intrauterine environment [11, $21,22]$. Unfortunately, in this study, we did not examine and diagnose definitive endometritis by scoring endometrial cytology, which is the most definitive and reliable method of doing so $[1,13,24]$. Therefore, in cows that experienced calving abnormalities, the intrauterine environments should be examined using endometrial cytology, and treated accordingly. To address this issue, dairy herdsmen and veterinary practitioners should pay special attention to assistance during calving, particularly in cases of dystocia or twinning. Considering potential risks of reduced fertility, it is vital to perform appropriate diagnosis and treatment for recovering uterine conditions. In the early postpartum period, it is well known that the uterine conditions change rapidly with spontaneous resolution. Therefore, vaginal discharges might constitute a part of the physiological self-cleaning process [6, 24]. Although vaginal discharge is an important part of symptoms of clinical endometritis, it does not necessarily reflect endometrium inflammation, and it indicates that some cows have the possibility of cervicitis without endometritis. $[9,25]$. In the present study, VDS test was performed at 21-60 days after parturition. Moreover, we diagnosed cows with a VDS of one or above for clinical endometritis under field conditions $[17,18]$. As mentioned above, uterine conditions during early postpartum period change rapidly. Therefore, for a more definitive and reliable diagnosis of clinical endometritis, evaluation of VDS test during the postpartum must be interpreted based on days (weeks) postpartum, and may be used in combination with endometrial cytology.

In conclusion, the occurrences of VDS of one or calving abnormality postpartum in dairy cows were shown to be possible risk factors for extending the number of days open, and consequently, a reduced reproductive performance of the herd. Previous studies have reported that other factors (e.g., housing system, mastitis, somatic cell count, and claw health) also affect reproductive performance in dairy herds negatively $[3,5,15]$. Future studies using a larger number of cows and farms, aimed at identifying the relationship of management with environmental factors and reproductive performance, are necessary under conditions relevant to Japan.

\section{REFERENCES}

1. de Boer, M. W., LeBlanc, S. J., Dubuc, J., Meier, S., Heuwieser, W., Arlt, S., Gilbert, R. O. and McDougall, S. 2014. Invited review: Systematic review of diagnostic tests for reproductive-tract infection and inflammation in dairy cows. J. Dairy Sci. 97: 3983-3999. [Medline] [CrossRef]

2. Fricke, P. M. and Wiltbank, M. C. 1999. Effect of milk production on the incidence of double ovulation in dairy cows. Theriogenology 52: 1133-1143. [Medline] [CrossRef]

3. Fuenzalida, M. J., Fricke, P. M. and Ruegg, P. L. 2015. The association between occurrence and severity of subclinical and clinical mastitis on pregnancies per artificial insemination at first service of Holstein cows. J. Dairy Sci. 98: 3791-3805. [Medline] [CrossRef]

4. Gaafar, H. M. A., Shamiah, SM., El-Hamd, M. A., Shitta, A. A. and El-Din, M. A. 2011. Dystocia in Friesian cows and its effects on postpartum reproductive performance and milk production. Trop. Anim. Health Prod. 43: 229-234. [Medline] [CrossRef]

5. Gautam, G., Nakao, T., Yusuf, M. and Koike, K. 2009. Prevalence of endometritis during the postpartum period and its impact on subsequent reproductive performance in two Japanese dairy herds. Anim. Reprod. Sci. 116: 175-187. [Medline] [CrossRef]

6. Gautam, G., Nakao, T., Koike, K., Long, S. T., Yusuf, M., Ranasinghe, R. M. and Hayashi, A. 2010. Spontaneous recovery or persistence of postpartum endometritis and risk factors for its persistence in Holstein cows. Theriogenology 73: 168-179. [Medline] [CrossRef]

7. Giuliodori, M. J., Magnasco, R. P., Becu-Villalobos, D., Lacau-Mengido, I. M., Risco, C. A. and de la Sota, R. L. 2013. Clinical endometritis in an Argentinean herd of dairy cows: risk factors and reproductive efficiency. J. Dairy Sci. 96: 210-218. [Medline] [CrossRef]

8. Goto, A., Nakada, K. and Katamoto, H. 2016. The association of culling and death rate within 30 days after calving with productivity or reproductive performance in dairy herds in Fukuoka, Southern Japan. J. Vet. Med. Sci. 78: 587-592. [Medline] [CrossRef]

9. Hartmann, D., Rohkohl, J., Merbach, S., Heilkenbrinker, T., Klindworth, H. P., Schoon, H. A. and Hoedemaker, M. 2016. Prevalence of cervicitis in dairy cows and its effect on reproduction. Theriogenology 85: 247-253. [Medline] [CrossRef]

10. Hayes, E. P., Christley, R. M. and Dobson, H. 2012. Effects of periparturient events on subsequent culling and fertility in eight UK dairy herds. Vet. Rec. 170: 540. [Medline] [CrossRef]

11. Hossein-Zadeh, N. G. 2010. The effect of twinning on milk yield, dystocia, calf birth weight and open days in Holstein dairy cows of Iran. J. Anim. Physiol. Anim. Nutr. (Berl.) 94: 780-787. [Medline] [CrossRef]

12. Kinsel, M. L., Marsh, W. E., Ruegg, P. L. and Etherington, W. G. 1998. Risk factors for twinning in dairy cows. J. Dairy Sci. 81: 989-993. [Medline] [CrossRef]

13. Leutert, C., von Krueger, X., Plöntzke, J. and Heuwieser, W. 2012. Evaluation of vaginoscopy for the diagnosis of clinical endometritis in dairy cows. J. Dairy Sci. 95: 206-212. [Medline] [CrossRef]

14. Livestock improvement association of Japan Inc. 2017. Flash report of dairy breed abilities test. http://liaj.lin.gr.jp/japanese/newmilk/17/ H28sokuhou.pdf (in Japanese) [accessed on January 29, 2018].

15. Lomander, H., Svensson, C., Hallén-Sandgren, C., Gustafsson, H. and Frössling, J. 2013. Associations between decreased fertility and management factors, claw health, and somatic cell count in Swedish dairy cows. J. Dairy Sci. 96: 6315-6323. [Medline] [CrossRef]

16. McDougall, S., de Boer, M., Compton, C. and Leblanc, S. J. 2013. Clinical trial of treatment programs for purulent vaginal discharge in lactating dairy cattle in New Zealand. Theriogenology 79: 1139-1145. [Medline] [CrossRef]

17. Okawa, H. and Fujikura, A. 2017. Prevalence and risk factors of clinical endometritis diagnosed by vaginoscopy in dairy herds. Jpn. J. Large Anim. Clinics 7: 225-230.

18. Okawa, H., Fujikura, A., Wijayagunawardane, M. M. P., Vos, P. L. A. M., Taniguchi, M. and Takagi, M. 2017. Effect of diagnosis and treatment of clinical endometritis based on vaginal discharge score grading system in postpartum Holstein cows. J. Vet. Med. Sci. 79: 1545-1551. [Medline] [CrossRef]

19. Plöntzke, J., Madoz, L. V., De la Sota, R. L., Heuwieser, W. and Drillich, M. 2011. Prevalence of clinical endometritis and its impact on reproductive performance in grazing dairy cattle in Argentina. Reprod. Domest. Anim. 46: 520-526. [Medline] [CrossRef]

20. Prunner, I., Wagener, K., Pothmann, H., Ehling-Schulz, M. and Drillich, M. 2014. Risk factors for uterine diseases on small- and medium-sized dairy farms determined by clinical, bacteriological, and cytological examinations. Theriogenology 82: 857-865. [Medline] [CrossRef] 
21. Salasel, B., Mokhtari, A. and Taktaz, T. 2010. Prevalence, risk factors for and impact of subclinical endometritis in repeat breeder dairy cows. Theriogenology 74: 1271-1278. [Medline] [CrossRef]

22. Sasaki, Y., Uematsu, M., Kitahara, G., Osawa, T. and Sueyoshi, M. 2014. Effects of stillbirth and dystocia on subsequent reproductive performance in Japanese Black cattle. Vet. J. 200: 462-463. [Medline] [CrossRef]

23. Silva del Río, N., Stewart, S., Rapnicki, P., Chang, Y. M. and Fricke, P. M. 2007. An observational analysis of twin births, calf sex ratio, and calf mortality in Holstein dairy cattle. J. Dairy Sci. 90: 1255-1264. [CrossRef]

24. Sheldon, I. M., Lewis, G. S., LeBlanc, S. and Gilbert, R. O. 2006. Defining postpartum uterine disease in cattle. Theriogenology 65: $1516-1530$. [Medline] [CrossRef]

25. Westermann, S., Drillich, M., Kaufmann, T. B., Madoz, L. V. and Heuwieser, W. 2010. A clinical approach to determine false positive findings of clinical endometritis by vaginoscopy by the use of uterine bacteriology and cytology in dairy cows. Theriogenology 74: 1248-1255. [Medline] [CrossRef]

26. Wiltbank, M. C., Fricke, P. M., Sangsritavong, S., Sartori, R. and Ginther, O. J. 2000. Mechanisms that prevent and produce double ovulations in dairy cattle. J. Dairy Sci. 83: 2998-3007. [Medline] [CrossRef] 